\title{
El silencio administrativo en la
} nueva Ley de la jurisdicción contencioso-administrativa

\section{1.-El silencio administrativo antes de la nUeva Ley}

1. No hace mucho tiempo, pero cuando aún de la nueva Ley sobre la jurisdicción contencioso-administrativa no se conocía ni el proyecto, me he ocupado de los problemas que planteaba el silencio administrativo (1). Ya en aquella ocasión estimé que la base de partida para un adecuado planteamiento de la cuestión estaba en considerar que con el silencio administrativo no se había querido-como regla-proporcionar una fórmula para interpretar la voluntad administrativa en supuestos en que ésta se manifestaba dudosa, pues justamente lo común a todas las hipótesis de silencio administrativo era la total falta de voluntad administrativa, sino crear una institución que sirviese de garantía a los derechos de los particulares: por virtud del silencio, lo que la Administración no. concedía podía solicitarse de la jurisdicción revisora competente.

También advertía allí que el silencio administrativo, peśe a la común denominación con que se le invocaba, no constituía en nuestro ordenamiento ninguna "doctrina" aplicable como supletoria de la Ley, pues, antes bien, ha sido la jurisprudencia la que ha repetido hasta la reiteración "... que la doctrina del silencio adminis-

(1) En mi trabajo Lo llamada doctrina del silencio administrativo, en Rev. do Adm. púb.s, núm. 10, enero-abril 1955, págs. $85 \mathrm{~g}$ ss. 
trativo solamente procede en virtud de precepto expreso. de la Ley" (2).

2. Si el silencio administrativo no es realmente sino un mecanismo que posibilita el acceso a la jurisdicción contenciosa allí donde la pasividad administrativa lo hubiera hecho imposible, parece que deba descartarse $a b$ initio una discusión acerca de sus efectos positivos o negativos, esto es, acerca de si el hecho de que la Administración no conteste una petición o reclamación de un particular dentro de un determinado plazo, se convierte ope legis en una estimación o desestimación de tal pretensión. Mas es el caso que, si bien la regla general es que nuestro Derecho positivo (tanto el relativo a la esfera central como a la local) configura el silencio como una ficción legal de desestimación de lo que el particular pretende (3), no faltan preceptos en los que se consagra precisamente la solución inversa: el valor positivo del silencio administrativo. El fundamento de este aparente (y a veces real) disparate jurídico no es siempre el mismo, por lo que merece la pena de que nos paremos en el examen de los diversos supuestos:

a) En primer lugar, debemos de referirnos al Reglamento de procedimiento administrativo en el Ministerio de Trabajo de 2 de abril de 1954. En el artículo 28 se dice : "Transcurridos cuatro meses desde la presentación de un escrito o recurso, o desde que se agote el plazo reglamentario para dictar resolución, sin que la autoridad competente haya dictado acuerdo definitivo, el interesado podré solicitar que se resuelva su petición. Si a los dos meses de haberse formulado tal requerimiento no hubiese recaído resolución, se considerará estimada tácitamente la petición deảucida". Late en el fondo de este irrealizable precepto-irrealizable por lo que después se dirá-la indudable buena intención que se apoya en la creencia de que, de esta forma, la Administración procurará ser más diligente en el despacho de sus asuntos, sobre todo si se tiene en cuenta que se hace responsable al funcionario causante del retraso

(2) Asi lo declaró la jurisprudencia de agravios: $O$ : de la $\operatorname{Pr}$. de 12 de enero de $13 \overline{r i}$; $B$. O. da: E. de 21 de ensro).

(3) Esta es la tesis que mantuvimos en nuestro antes citado trabajo. 
de los posibles perjuicios que la aplicación del silencio positivo comporte. Pero ocurre-y ello es obvio-, que muchas veces podrán producirse perjuicios irreparables para la Administración pública, que no podrán aminorarse ni por el ingenuo expediente de castigar al funcionario negligente, ni siquiera por el más efectivo de hacerle responder patrimonialmente de daños y perjuicios, pues el interés público sólo en pocas ocasiones es convertible en dinero.

Por otra parte, puede ocurrir que con el acto obtenido por aplicación de esta modalidad del silencio se lesionen derechos administrativos o intereses legítimos de terceros que, desconociendo lo que ha ocurrido (pues el silencio sí que se habrá producido para ellos con el valor literal que el vocablo tiene), no podrán recurrir en defensa de sus situaciones; aparte las dificultades lógicas de un recurso que ciertamente habría de dirigirse contra la Administración para convencerla de que debe declarar expresamente que lo que no ha hecho efectivamente no ha debido hacerlo. Pero hay más aún: puede presumirse que esta institución no tendrá eficacia práctica alguna en orden a los extraordinarios beneficios que parecen concederse a los particulares. En efecto, una vez que se haya producidō el silencio con valor estimatorio ¿cómo obligar a la Administración a que ejecute dicho acto administrativo tácito?

En fin, el silencio positivo es una solución absurda cuyas ventajas son mínimas en relación con sus muchos inconvenientes, como pusieron de relieve los conocidos argumentos de Royo Villanova: bastará en muchos casos la négligencia o falta de celo de los funcionarios administrativos para que los particulares se conviertan en administradores ; cualquier petición, incluso la más absurda, de un particular, puede convertirse en un título jurídico a su favor, por el soblo hecho de que un plazo ha transcurrido.

b) Hay, otros casos en que la técnica del silencio positivo juega en relación con la petición de autorización o aprobación a cargo de autoridades superiores respecto de actos de organismos sometidos a su inspección o tutela. La vigente Ley de Régimen local de 24 de junio de 1955 of rece ejemplos de esta forma de silencio positivo. Así, el artículo 110 regula los poderes de control del Gobernador civil sobre las ordenanzas o reglamentos municipales; pues 
bien, "si el Gobernador civil no hiciese ninguna advertencia de ilegalidad dentro del plazo de treinta días... las ordenanzas y reglamentos tendrán carácter ejecutivon.

Aquí la hipótesis difiere ciertamente de la que hemos analizado en el apartado anterior, hasta el punto de que, hasta cierto punto, cabría intentarse una justificación no atentatoria contra la que hemos señalado ser verdadera naturaleza del silencio administrativo. - Porque aquí la aplicación del silencio positivo está de acuerdo con el principio que predica la presunción de legitimidad para los actos de las entidades públicas, incluídas las locales. Como dice Royo Villanova (4), cabe pensar que aquí el legislador ha impuesto realmente a la autoridad superior un plazo para el ejercicio de sus facultades de control; si este plazo es de caducidad, entonces el efecto que se consigue es precisamente el del silencio positivo.

Es cierto que con esto no se elimina radicalmente el peligro de que ciertos actos inconvenientes de los organismos inferiores escapen a una debida corrección por parte de los superiores. Pero, a la postre, se trata de un peligro que no hay inconveniente en correr.

c) El intento técnicamente más logrado que se contiene en nuesrras leyes de matizar una distinción entre los supuestos de silencio positivo y negativo, se descubre en el Reglamento de servicios de las Corporaciones locales de 17 de junio de 1955. Después de declarar en su artículo $80^{\circ}$ que clas Corporaciones podrán sujetar a sus administrados al deber de obrener previa licencia en los casos previstos por la Ley, el presente reglamento u otras disposiciones de carácter general", determina en el artículo siguiente el procedimiento a seguir para la obtención de las mismas. En el número $5 .^{\circ}$ del mismo artículo se señalan los plazos en que las licencias deben otorgarse o denegarse y en el número $7 .^{\circ}$ se declaran los efectos que produce el transcurso de dichos plazos sin que se haya producido notificación de resolución expresa. Tales efectos son:

(4) El silencio positivo de la Administración y sie interrapción en sinateric minai.

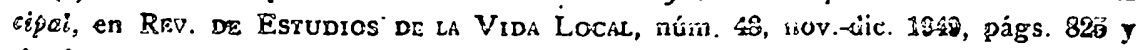
sigvientes. 
(a) El peticionario de licencia de parcelación... construcción de inmuebles o modificación de estructura de los mismos, implantación de nuevas industrias o reformas mayores de las existentes, podrá acudir a la Comisión provincial de Urbanismo, donde existiere constituída, o, en su defecto, a la Comisión provincial de servicios técnicos, y si en el plazo de un mes no se notificare al interesado acuerdo expreso, quedará otorgada la licencia por silencio administrativo.

b) Si la licencia solicitada se refiere a actividades en la vía pública o en bienes de dominio público o patrimoniales, se entenderá denegada por silencio administrativo.

c) Si la licencia instada se refiere a obras o instalaciones menores, apertura de toda clase de establecimientos y, en general, cualquier otro objeto no comprendido en los dos apartados precedentes, se entenderá otorgada por silencio administrativion.

Aquí parece que el legislador ha tenido en cuenta que los supuestos que se contienen en los apartados a) y c) difieren suficientemente del contemplado en el apartado $b$ ), hasta el punto de justificár soluciones distintas en materia de silencio administrativo. En efecto, en aquellos casos el peticionario solicita siempre una autorización de policía, es decir, la remoción de un obstáculo que se opone al ejercicio de una actividad de la que, empero, debe considerársele titular originario. Quien quiere reparcelar no pretende, en principio, sino disponer en un determinado sentido de su propiedad urbana; quien quiere implantar una industria o abrir un nuevo establecimiento mercantil, está haciendo uso de una libertad que tradicionalmente se ha considerado amparada por la Constitución : la libertad de industria y comercio. El silencio positivo, en suma, no significa aquí-así debe haberio creído el legisladorconvertir al administrado en administrador.

La distinta solución del apartado b) encontraría, sin embargo, su fundamentación en las propias consideraciones. En relación con el dominio público, los particulares sólo tienen un derecho originario al uso común establecido ; todo aprovechamiento que desborde tales límites (como parecen serlo las actividades aludidas en el apartado b) que se comenta) sólo puede obtener titulación jurídica mediante un expreso otorgamiento por parte de la Administración 
titular del bien. Otro tanto cabe decir en relación con los bienes patrimoniales, respecto de los que la Corporación local se encuentra en relación análoga a la de los propietarios particulares con sus bienes. El silencio positivo en estos casos daría por resultado trasladar sin más a los particulares facultades propias de la titularidad dominial.

Cualquiera que sea la bondad teórica de la argumentación que se ha expuesto, insisto en manifestarme discrepante de estos casos positivos de silencio. Todas las razones que justifican las reglamentaciones policiales (de la propiedad privada, como de cualquiera de lâs libertades constitucionales) vienen a ser traicionadas sistemáticamente con una tal sólución. Pensemos, por ejemplo, en la petición de licencia de apertura de establecimientos mercantiles o industriales. La base legal de la necesidad de la licencia está en el artículo 22 del Reglamento, que dice: “1. Estará sujeta a licencia la apertura de establecimientos industriales y mercantiles.-2. La intervención municipal tenderá a verificar si los locales $e$ instalaciones reúnen las condiciones de tranquilidad, seguridad y salubridad, y las que, en su caso, estuvieren dispuestas en los planes de urbanismo debidamente aprobados". Está claro que la fiscalización de si existen estas condiciones de tranquilidad, salubridad, etc.--y, por ende, la existencia misma de las condiciones-puede quedar burlada en una licencia obtenida al amparo del mecanismo ciel silencio administrativo. Se hace así pagar a la comunidad-que es realmente la interesada en que las industrias sean tranquilas o ruidosas, salubres o insalubres, seguras o peligrosas-la inercia o pasividad de los funcionarios y autoridades municipales. $\mathrm{Ni}$ aun en el caso de que después se exigiesen responsabilidades personales a los culpables, podría evitarse, ni siquiera compensarse a posteriori, el daño soportado por la comunidad.

La solución es tanto más criticable si se tiene en cuenta que se pueden arbitrar otras que, sin abandono de la esencial preccupación por los derechos e intereses de los particulares, sean más acordes con el interés público. En este sentido parece orientarse el párrafo $4 .^{\circ}$ del artículo 12 de la Ley de Minas de 19 de julio de 1944 , al determinar que los expedientes a que da lug̣ar la petirión de un 
permiso de investigación minera deberán ultimarse en el plazo máximo de ocho meses, y si transcurriese dicho plazo "sin que hubiese recaído acuerdo, y siempre que en el período oportuno no se hubiesen formulado oposiciones, el solicitante podrá comenzar los trabajos bajo su responsabilidad y sin perjuicio de los derechos de terceros, a reserva de la definitiva resolución del expediente).

3. Aun reduciéndonos al ámpito del silencio administrativo negativo, pues, con todo, el positivo sigue siendo en nuestro Derecho la excepción, la legislación y jurisprudencia anteriores a la nueva Ley daban lugar a un rico repertorio de problemas, los más importantes de los cuales se refieren a continuación:

a) En relación con el plazo que debe transcurrir para que se entiendan producidos los efectos del silencio, la variedad establecida en relación con los distintos organismos administrativos es casi absoluta. Incluso dentro de un mismo organismo, los plazos varían según el tipo de expediente de que se trate. Así, por vía de ejemplo, en el Ministerio de Educación Nacional (según la Orden ministerial de 3 de diciembre de 1947) los recursos entablados contra organismos dependientes de la Subsecretaría y Direcciones generaies se considerarán denegados por el mero transcurso de dos meses, mientras que las alzadas contra estas últimas autoridades necesitan, para que les sea aplicable el silencio, el transcurso de un plazo de cuatro meses.

b) Entre los Ministerios cuyo Reglamento de procedimiento administrativo aceptan el silencio (que no son todos), no se admite siempre con la misma extensión; en algunos casos el silencio. se da en relación con cualquier asunto planteado por un particular a la Administración pública, bien en vía de petición, bien en vfa de recurso; en otros casos, el silencio se reserva para los asuntos planteados en vía de recurso. Esto último es lo más general; pero. debe recordarse que los Reglamentos de los Ministerios de Gobernación, Trabajo e Industria admiten el silencio en ambas vías. Esta misma extensión tiene en la vigente Ley de Régimen local.

c) Otra cuestión es la relativa a si el silencio debe producirse automáticamente por el mero transcurso del plazo establecido o si se exige al particular la previa denuncia de la mora. La anarquía 
iegislativa que impera en la materia hace que cada Ministerio haya clegido su propia solución. Parece, en principio, que el sistema del silencio automático es más propio de aquellos supuestos en que la institución sólo se aplica al ámbito de la vía de recurso, mientras que el sistema de denuncia de la mora sea más acorde con las exigencias de la vía de petición. No obstante, el ejemplo de nuestro Derecho positivo no abona estas conclusiones. $\mathrm{Y}$ asf, si bien es cierto que la Ley de 18 de marzo de 1944, creadora de la jurisdicción de agravios, y la Orden ministerial de 3 de diciembre de 1947 para los recursos en el Ministerio de Educación Nacional, consignaron la producción automática del silencio aplicable a la vía de recurso, también lo es que los Reglamentos del Ministerio de la Gobernación, de 31 de enero de 1947, y de Industria, de 7 de septiembre de 1954, exigen la denuncia de la mora lo mismo en vla de recurso que en vía de petición. Mención especial merece, por ajustarse a los principios antes expuestos, la vigente Ley de Régimen local: en su artículo 374 consigna el mecanismo de la denuncia de la mora para que el silencio se produzca en vía de petición, mientras que en el artículo 377 admite la prociucción automática del silencio en vía de recurso de reposición.

d) Pertenece al ámbito de las cuestiones resueltas jurisprudencialmente la relativa a la determinación de los efectos que producen las resoluciones administrativas que han sido acordadas una vez transcurrido el plazo del silencio administrativo. Estos efectos pueden ser contemplados desde dos distintas perspectivas: la perspectiva procesal y la que ofrece el Derecho material.

$\left.a^{\prime}\right)$ Desde el punto de vista procesal se trata simplemente de saber si la resolución tardía de la Administración rehabilita los plazos para recurrir, supuesto que no se hubiesen utilizado los oportunos recursos contra la resolución denegatoria producida por el transcurso del plazo del silencio administrativo. Una continuada jurisprudencia contencioso-administrativa y de agravios-con sólo muy loables excepciones-ha venido consagrando la arbitrariedad de que tal rehabilitación no se daba, o lo que es lo mismo, que la única oportunidad que el particular teńa de recurrir era a partir del momento en que vela transcurrido el plazo del silencio sin que 
ia Administración se hubiese pronunciado. Ýa veremos la corrección oportunísima que aquí introduce la nueva Ley.

b') Desde el punto de vista del Derecho material la cuestión se reduce a saber si el organismo administrativo pierde o no su competencia para resolver un asunto una vez que ha transcurrido el plazo del silencio. La jurisprudencia del Tribunal Supremo ha pasecido inclinarse a la pérdida de tal competencia; punto de vista que no compartía la jurisdicción de agravios hasta un importante acuerdo del Consejo de Ministros de 5 de marzo de 1954 (“B. O. del Estadon de 2 de octubre) en el que se declaraba la nulidad de un acuerdo administrativo porque fué adoptado cuando el organismo en curestión "carecía de jurisdicción para resolver sobre el recurso interpuesto toda vez que... había transcurrido con exceso el plazo de'treinta días... como término dentro del cual puede válida y expresamente ser denegado un recurso de reposiciónn. Afortunadamente esta doctrina no ha sido la más frecuentemente mantenida por agravios. En cualquier caso, la nuevà Ley resuelve definitivamente la cuestión, como también veremos.

\section{1.-La regulación en la nueva Ley de 27. De diciembre de 1956}

4. Varios son los preceptos de la nueva Ley donde se habla del silencio administrativo. A la vista de lo que era el Derecho anterior, la nueva regulación-como manifestaba Royo Villanova en su brillante discurso de presentación del proyecto de Ley al Pleno de las Cortes españolas-supone una innovaciớn verdaderamente importante. Hay que subrayar que a ella ha ido el legislador conscientemente, con pleno conocimiento de cuál era el problema, como se desprende de las propias palabras de la exposición de motivos, donde se dice que "... la Ley instituye un régimen general de silencio administrativo, mediante el cual, transcurrido cierto plazo, puede presumirse por el interesado la existencia de un acto que le per- mita el acceso, si lo desea, a la jurisdicción contencioso-administrativa". Está claro que este "régimen general" que abarca principalmente la vía de petición, pero que puede aplicarse a la de recurso, y que deroga, en su caso, algunos reglamentos de procedi- 
miento administrativo, no tiene, en puridad, su adecuado lugar sistemático en una Ley procesal de la jurisdicción contencioso-administrativa. Pero el legislador, y hemos de elogiarlo, ha aprovechado la oportunidad que se le ha brindado para resolver esta cuestión que tenía planteada nuestro Derecho positivo.

Se trata, pues, repetimos, de una regulación del silencio en vía de petición y en vía de recurso. En relación con la primera, dice el artículo 38,1 ) de la nueva Ley : "Cuando se formulare alguna petición ante la Administración y ésta no notificare su decisión en el plazo de tres meses, el interesado podrá denunciar la mora y, transcurridos tres meses desde la denuncia, podrá considerar desestimada su petición, al efecto de formular frente a esta denegación presunta el correspondiente recurso administrativo o jurisdiccional, según proceda, o esperar la resolución expresa de su petición".

Por lo que se refiere al silencio en vía de recurso, la Ley empieza por establecer, en su artículo 52, y como trámite previo a la interposición del recurso contencioso-administrativo, un recurso de reposición (salvo, precisamente, en el caso de que frente a una petición de un particular se haya producido el silencio a que antes nos hemos referido). Pues bien, de acuerdo con el artículo 54, 1) de ia Ley: "Transcurrido un mes desde la interposición del recurso de reposición sin que se notificare su resolución, se entenderá desestimado y quedará expedita la vía contencioso-administrativan.

Pero es que además el propio artículo 38 podría aplicarse a la vía de recurso en aquellos organismos cuyo procedimiento administrativo, por regularse por muy viejos textos reglamentarios, ni siquiera conoce el silencio administrativo en ciicha vía. En efecto, un recurso no deja de ser una "petición ante la Administración", a la que, a falta de un específico tratamiento en materia de silencio, puede aplicarse el del artículo 38.

A partir de estos preceptos fundamentales y de los que le sirven de complemento, la figura del silencio administrativo adquiere un nuevo perfil que contrasta, en muchos casos, con el que señalaba la legislación anterior. Tal contraste se pone de manifiesto en el pxamen de las siguientes cuestiones :

a) Ia prociucción del silencio se verifica ahora automáticamen- 
te, es decir, por el mero transcurso del plazo establecido, en relación con el recurso de reposición, mientras que en vía de petición se ha de acudir al procedimiento de la denuncia de la mora, a partir de cuyo momento se inicia el plazo de producción automática. Con esto no se hace sino generalizar la instrumentación que del silencio hacía la Ley de Régimen local y, ya dijimos anteriormente, que este era el sistema más lógico.

b) El problema de si la Administración pierde su competencia para resolver el asunto, una vez que el plazo del silencio administrativo ha transcurrido, ha sido resuelto por la nueva Ley de acuerdo con la naturaleza de la institución que se examina y en el mismo sentido-hemos de mostrarnos complacidos por ello-por nosotros defendido en anteríor trabajo ya citado. Pero la Ley añade aún un nuevo matiz: no se trata solamente de que la Administración puede, sino que debe resolver expresamente. La exposición de motivos dice, a este respecto : "el silencio administrativo, ciertamente, no puede ser conceptùado como un medio a través del cual la Administración pueda eludir su obligación de motivar las decisiones, como vendria a ser si por el silencio quedara exenta del deber de dictar un proveido expreso, debidamente fundadon. $\mathrm{Y}$ esto se recoge en forma de precepto en el artículo 38, 2) de la Ley : “En todo caso, la denegación presunta no excluirá el deber de la Administración de dictar una resolución expresa, debidamente fundadan.

Esta facultad, y deber simultáneamente, de resolver-expresamente el asunto después del silencio, no se extingue ni siquiera por el hecho de que el particular hubiese utilizado debidamente el recurso contencioso-administrativo, pues incluso esta hipótesis está contemplada por la Ley en el artículo 90, 1), que dice: "Si, interpuesto recurso contencioso-administrativo, la Administración demandada reconociese totalmente las pretensiones del demandante en via administrativa, cualquiera de las partes podrá ponerlo en conocimiento del Tribunal si la Administración no lo hicieran. Hay que reconócer, empero, que este supuesto sólo se dará extraordinariamente si la tramitación del recurso contencioso-administrativo está tan avanzada que ya se ha enviado el expediente administrativo al Tri- 
bunal ; pues el envfo de dicho expediente supone, al menos de facto, la pérdida de la competencia de la Administración sobre el asunto. A la Administración le debe estar vedado resolver "de memoria".

c) Otra cuestión que preocupó a la jurisprudencia anterior fué la relativa a la llamada "rehabilitación de los plazos para recurrir" a partir del momento, posterior al silencio, en que se produjera resolución expresa de la Administración. Aquí, la solución consagrada por la jurisprudencia no pudo ser más desafortunada. Co mentándola, en su oportunidad; decíamos nosotros: "el recurrente puede llegar a creer con fundamento que el llamado silencio administrativo, que tanto se le invoca, pero que no llega a entender, es una diabólica doctrina inventada por la Administración para que sus recursos nunca prosperen". También ahora nos hemos de felicitar que nuestro punto de vista, que intentaba fundarse en la que estimábamos que constitula la verdadera esencia del silencio administrativo, haya sido plenamente aceptado por la nueva Ley. En su exposición de motivos, en efecto, se lee: "Acudir a ella (a la vía contencioso-administrativa) se considera como una facultad y no como una obligación, con lo cual se restituye la figura del silencio administrativo al sentido que propiamente se le atribuyó originariamente, de garantía para los administrados frente a las demoras de la Administración". A partir de esta consideración hay que explicarse la última parte del artículo 38, 1): “...transcurridos tres meses desde la denuncia, podrá considerar desestimada su petición, al efecto de formular frente a esta denegación presunta el correspondiente recurso administrativo o jurisdiccional, según proceda, - esperar la resolución expresa de su peticiónn.

d) La nueva concepción del silencio administrativo tiene también efectos inmediatos en relación con los plazos para interponer el ulterior recurso contencioso-administrativo. La Ley distingue claramente según se trate de una resolución expresa de la Administración o de una desestimación en virtud de la aplicación del silencio. En el primer caso, el plazo es de dos meses a partir de la notificación del acuerdo (art. 58, 1); en el segundo caso, el plazo es nada menos que de un año; contado a partir de la interposición del recurso previo de reposición (art. 58, 2), o a partir del momento 
en que la desestimación tácita debió de producirse en vía de petición (art. 58, 4). Este largo plazo se justifica en la exposición de motivos : "esta diferenciación, formulada en el ámbito de la legislación local, es de indudable pertinencia; se acomoda perfectamente al nivel de formación $\mathrm{y}$ conocimiento de la gran mayoría de los administrados, a quienes no puede exigirse que obren como sólo sería posible hacerlo si la técnica del acto presunto, realizado por silencio administrativo, y los casos y plazos de éste fuesen de dominio general. No siéndolo así, fijar un plazo de dos meses para que puedan deducirse las reclamaciones correspondientes a las desestimaciones por silencio administrativo, equivale a condenar a indefensión a la gran masa de administrados españoles, y admitir que, para ellos, habrán de prevalecer casi siempre, por no interponer el recurso oportunamente, los actos no conformes a Derecho realizados en virtud de la sutil figura del silencio administrativon. Y para reforzar aún el argumento se añade: "Por otra parte, nada más fácil para la Administración que reducir ese plazo al de dos meses: le basta el sencillo procedimiento de dictar un acto expreson.

A pesar de la referencia que en la propia exposición de motivos hemos visto que se hace a la Ley de Régimen local, como fuente de inspiración en esta materia, hemos de señalar que aquí el plazo del año no tiene los efectos de ser-como en el artículo 388,2 ) de la Ley de Régimen local-un plazo de prescripción absoluta de la acción contencioso-administrativa (ya que en el sistema anterior la resolución expresa, pero tardía, no rehabilitaba los plazós de interposición), pues "si con posterioridad recae acuerdo expreson, de nuevo empieza a correr el plazo de dos meses. Ahora la Administración no pierde su competencia para resolver expresamente, ni siquiera transcurrido el año.

5. Hemos de preguntarnos ahora si la nueva regulación que del silencio administrativo se hace es derogatoria o supletoria de la que, sobre la materia, se contiene en las diferentes reglamentaciones de procedimiento administrativo.

Para responder, hemos de comenzar por saber qué dice el pro pio legislador en la exposición de motivos. Se lee all : "El régimen general instituído por la Ley carecerá, desde luego, de aplicación 
en aquellos supuestos en que otras disposiciones establezcan que, transcurrido cierto plazo, previa o no denuncia de la mora, hayan de entenderse estimadas las pretensiones de los administrados, pues en otro caso la Ley, que tiene por objeto instituir garantías de las sicuaciones juridicas de los administrađos, vendría precisamente a aminorarlas. Lo mismo habrá que considerar, por idéntica razón, cuando otros textos legales o reglamentarios establezcan, en beneficio de los interesados, plazos más reducidos que los que se prevén en esta Ley para que se entienda producido acto presunton.

Sobre esta base no resulta difícil establecer las reglas siguientes :

1. Frente al principio general de silencio negativo establecido en la Ley, rigen, como excepción, los casos de silencio positivo establecidos en reglamentos anteriores: por ejemplo, en el Reglamento del Ministerio de Trabajo de 2 de abril de 1954 (art. 28), o en el Reglamento de servicios de las Corporaciones locales (art. $9 .^{\circ}$ ).

2. Los reglamentos que contengan plazos más reducidos de producción del silencio prevalecerán frente a la Ley. A estos efectos debe entenderse que el plazo del artículo 38 de la Ley es de seis meses (dividido en dos períodos de tres meses, antes y después de la denuncia), por lo que puede señalarse, a modo de ejemplo, que el artículo 116 del Reglamento del Ministerio de la Gobernación debe seguir considerándose vigente ya que establece un plazo tocal para el silencio de cinco meses (cuatro antes de la denuncia de. la mora y uro después).

3. ${ }^{3}$ La nueva Ley regula directamenre-aparte el caso del recurso de reposición-el silencio en vía de petición, por lo que hay que entender que los plazos de resolución por silencio de recursos jerárquicos habrán de computarse tal como hasta ahora se encueniren regulados en los preceptos reglamentarios. Así, por ejemplo, habrá que entender que la Orden ministerial de 3 de diciembre de 1947 sobre los recursos en el Ministerio de Educación Nacional no ha sido afectada pcr la nueva Ley. Sin embargo, alli donde rijan reglamentos de procedimiento que no prevean la aplicación del silencio administrativo a los recursos gubernativos, éstos habrán de considerarse como "peticiones a la Administracién a los efectos del artículo 38 de la rueva Ley. 
4. El recurso de reposición se concibe en la nueva Ley más como trámite previo al ejercicio de la acción contencioso-administrativa que como parte integrante de la vía gubernativa, por tanto, el plazo de un mes para que se entienda desestimado por silencio rige con derogación del de quince días que establecía la Ley de Régimen local en su artículo 377, no obstante que éste último sea menor. La nueva Ley puede considerarse supletoria en materia de procedimiento administrativo, pero en relación con el contenciosoadministrativo es la única vigente.

Fernando Garrido falla

Catedrático de Derecho Administrativo. 